\title{
The definition of WHAT-d'you-call-it: semantics and pragmatics of recognitional deixis
}

\author{
N.J. Enfield \\ Max Planck Institute for Psycholinguistics, PO Box 310, 6500 AH Nijmegen, The Netherlands
}

Received 13 July 1998; received in revised form 9 April 2002

\begin{abstract}
Words such as WHAT-d'you-call-it raise issues at the heart of the semantics/pragmatics interface. Expressions of this kind are conventionalised and have meanings which, while very general, are explicitly oriented to the interactional nature of the speech context, drawing attention to a speaker's assumption that the listener can figure out what the speaker is referring to. The details of such meanings can account for functional contrast among similar expressions, in a single language as well as cross-linguistically. The English expressions WHATd'you-call-it and you-know-WHAT are compared, along with a comparable Lao expression meaning, roughly, 'that thing'. Proposed definitions of the meanings of these expressions account for their different patterns of use. These definitions include reference to the speech act participants, a point which supports the view that WHAT-d'you-call-it words can be considered deictic. Issues arising from the descriptive section of this paper include the question of how such terms are derived, as well as their degree of conventionality. (C) 2002 Published by Elsevier Science B.V.
\end{abstract}

Keywords: Deixis; Interaction; Common ground; Semantics/pragmatics interface; Convention; Lao

\section{Introduction}

Words like WHAT-d'you-call-it ${ }^{1}$ are seldom discussed in linguistic theory, yet they raise both fascinating and fundamental questions about the nature of linguistic meaning. To figure out what such expressions actually refer to on any given occasion, interlocutors must rely especially heavily on knowledge assumed to be shared.

E-mail address: nick.enfield@mpi.nl (N.J. Enfield).

1 Arbitrarily, I use the spelling WHAT-d'you-call-it, intended to cover variation in pronunciation from

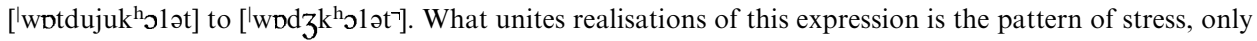
on the first element WHAT. In this respect, this is formally distinct from the compositional question WHAT do you CALL it? ['wptduju'k'ərat], which places primary stress on call (see Section 3.4, below). 
In this sense, expressions like WHAT-d'you-call-it vividly illustrate the property of linguistic practice as 'joint action' (Clark, 1996a) — when John turns to Mary and says Pass me the WHAT-d'you-call-it, he provides her with no descriptive information about the thing he is referring to, but nonetheless he is likely to succeed in communicating what he means. Expressions of this kind are interesting not only because they explicitly depend on interlocutors' 'inter-recursive' common ground (i.e. not just 'what we both know', but 'what we each assume that we each assume that we both know'; Enfield, 2000: 45) for successful reference to be made (as deictic elements and anaphors do generally), but also because they have semantic specifications which subtly account for the interpretations hearers make. It is not literally the case that these expressions are 'vacuous' (pace Levinson, 1995: 232, Clark, 1996b: 331). It emerges from the examples discussed in this paper that, firstly, expressions of this kind have meanings which are explicitly oriented to the interactional nature of the speech context, drawing attention to the speaker's assumption that the listener can figure out what the speaker is referring to, and, secondly, that the details of such meanings can account for functional contrast among similar expressions, in a single language as well as cross-linguistically.

The paper contains two main sections. The first section concentrates on data, describing and comparing pragmatic and semantic properties of the English expressions WHAT-d'you-call-it and you-know-WHAT, as well as a specific use of the Lao distal demonstrative $n a n^{4}$ 'that', which has a primarily (but not exclusively) euphemistic function in the phrase $q a n^{0}-n a n^{4}$ 'that thing'. A feature of this section is the proposal of explicit definitions of the meanings of these expressions. The second section discusses a number of theoretical and methodological issues which arise: first, the claim that WHAT-d'you-call-it and similar expressions are deictic expressions of a certain kind (i.e. 'recognitional' deictics); second, the problem of where and how to draw the line between semantics and pragmatics in the description of these expressions and their use, and what to make of the suggestion that the proposed meanings are merely 'conditions of use'; third, the status of these expressions as more or less grammaticalised, in comparison to explicitly compositional counterparts such as the sentence What do you call it? and You know what; fourth, the relative conventionality of these expressions in the linguistic system. The English expressions WHAT-d'you-call-it and you-know-WHAT show a significant degree of conventionality, but there are nevertheless many other words - e.g. doodad, whatsit, thingamejig - which do a very similar job. Furthermore, completely novel forms can conventionally perform similar functions in small, closed speaker groups. The paper concludes with brief closing remarks.

\section{Semantics and pragmatics of WHAT-d'you-call-it and you-know-WHAT}

\subsection{WHAT-d'you-call-it}

Suppose Mary is power-drilling and John is nearby. She mislays the chuck key while changing drill-bits, and the following exchange ensues: 
(1) Mary: John, where's the WHAT-d'you-call-it? John: I put it back in the toolbox.

The exchange is a success.

Mary meant 'Where's the chuck key?' but she did not use the expression chuck key. She was thinking of the thing, and could not think of the word for it. (This may indeed have been because she did not know the word for it.) A specific referent for the very non-specific expression WHAT-d'you-call-it was not only in Mary's mind, but she expected John to understand that she was talking about 'the chuck key' on the basis of this semantically extremely general term alone. And he did, naturally, since he knew what Mary had to be talking about. According to the usual powerdrilling scenario - part of John and Mary's shared cultural common ground-the chuck key was right then crucially required, before any further progress in the task at hand could be made. The success of this exchange requires that both Mary and John know these details of the typical power-drilling scene, that they each know (or assume) that the other knows, and further that they each know (or assume) that the other knows that they themselves know (Enfield, 2000: 45). This is what is required for the term WHAT-d'you-call-it to successfully denote in this case 'the chuck key' (the thing), by means of inferential processes which rely on mutually assumed cultural scenarios as interpretative resources. And while successful reference in virtually any communication requires this (e.g. when John says The car won't start, Mary knows which car he means), the term WHAT-d'you-call-it (unlike car) provides next to no descriptive information to narrow down possible reference (among virtually every nameable thing!).

However, the successful communication achieved in example (1) cannot have relied exclusively on shared non-linguistic knowledge/assumptions in the given context. The interpretation is constrained by stable context-independent semanticshowever schematic they may be-of the expression WHAT-d'you-call-it. By saying WHAT-d'you-call-it, Mary provides John with very much less specific constraints on interpretation than if she had said chuck key, but nevertheless still provides concrete clues, namely that she was talking about something, that she could not produce the word for this thing right then, but that she thought John would know what she was talking about. ${ }^{2}$ These aspects of the message of WHAT-d'you-call-it can be viewed as part of its stable meaning. This is why Mary chose the word WHAT-d'you-call-it in the context of (1) and not a random word like table, carburettor, or the (let alone a nonsense syllable or a non-linguistic noise). The term is to some degree conventionalised (see Section 3.5, below, for discussion), and as such has a relatively stable meaning and can be relied upon in just such contexts to lead the hearer to the right interpretation.

Based on the discussion so far, it is possible to suggest an explicit definition (in the form of a paraphrase of the speaker's message; Goddard, 1998: 18) for WHAT-d'youcall-it: ${ }^{3}$

\footnotetext{
${ }^{2}$ I acknowledge that the definite article the in (1) also contributes to the message that the referent is assumed to be given knowledge for speaker and listener. However, this does not affect the general point being made about the expression WHAT-d'you-call-it and its contrast with similar expressions.

3 The components of the definition are meant as non-optional parts of a single complex meaning.
} 
(2) WHAT-d'you-call-it:

- Something

- I can't say the word for this thing now

- By saying WHAT-d'you-call-it I think you'll know what I'm thinking of.

The details of this definition account for restrictions on the usage of the expression. First, Mary had to be talking about something, which best refers to objects (referred to by count nouns) like chuck keys, but also to substances (referred to by mass nouns), like sodium bicarbonate, oral rehydration salts, and vitamin E cream:

(3) There were traces of WHAT-d'you-call-it at the bottom of the test-tube.

(4) I need to drink some WHAT-d'you-call-it.

(5) You should put some WHAT-d'you-call-it on that dry skin.

That WHAT-d'you-call-it should refer to 'something' accounts for its relative oddity (but not necessarily infelicity) in place of adjectives, and especially in place of inflected verbs and determiners:

(6) ?John is far too WHAT-d'you-call-it.

(7) ?Mary said she would WHAT-d'you-call-it the council on John's behalf.

(8) ??Mary WHAT-d'you-call-it-ed the council on John's behalf.

(9) *There were WHAT-d'you-call-it people there. ${ }^{4}$

Second, according to the definition in (2), Mary's use of the word WHAT-d'youcall-it conveys that she cannot think of the word for the thing she wants to refer to, (i.e. chuck key 'chuck key'). ${ }^{5}$ This accounts for the following contrast:

(10) Where's the WHAT-d'you-call-it?..., you know, the chuck key?

(11) *Where's the chuck key?..., you know, the WHAT-d'you-call-it?

In (10), the speaker at first cannot think of the word, and then is able to be more specific a moment later when the word comes to mind. This represents a natural and common flow of events. Example (11) presents the opposite sequence, which does

\footnotetext{
${ }^{4}$ This example is rejected with primary stress on the head of the noun phrase, i.e. with the same intonation as There were seven PEOPLE there, and not with the same intonation as There were ANGOLAN people there.

5 The second component of (2) states that there is indeed 'a word' for the thing, as the presence of the word call in the form WHAT-d'you-call-it suggests. Indeed, as one anonymous reviewer pointed out, this specification is one way of narrowing possible reference of this semantically very general expression.
} 
not make sense, as predicted by (2). ${ }^{6}$ The speaker who utters WHAT-d'you-call-it in (11) obviously can think of the word for the thing she is thinking of, since she has just uttered it.

Third, by the definition in (2), in saying WHAT-d'you-call-it the speaker conveys that she assumes the addressee knows (or can know) what she is thinking of once she has said the word. Given the context of her utterance in (1), Mary can quite well make this assumption of John. However, if John were somewhere on the other side of town, with no idea of what Mary was doing, and she called him on the telephone and uttered the string in (1) with no contextual set-up (not that much would be needed), communication would fail. John would naturally be confused at Mary's assumption - explicitly communicated by her use of the expression WHAT-d'you-callit - that he should know what she means.

These observations about WHAT-d'you-call-it apply, mutatis mutandis, to WHAT'Sher-name and WHAT'S-his-name. These expressions refer to people rather than to things, maintaining a gender distinction in the incorporated third-person singular pronouns. The following definition of WHAT's-his-name shows the parallels:

(12) WHAT's-his-name

- Someone (male)

- I can't say this person's name now

- By saying WHAT's-his-name I think you'll know who I'm thinking of.

\subsection{You-know-WHAT ${ }^{7}$}

Despite the semantic generality and heavy context-reliance of expressions like WHAT-d'you-call-it, they nevertheless contrast with similar expressions in essentially predictable ways. Compare (1) with the following:

(13) Mary: John, where's the you-know-WHAT?

In both (13) and (1) Mary does not say the word for the thing she is thinking about, and also in both cases by using a 'vacuous' word, she is assuming that John knows (or can figure out) what she is talking about. [Indeed, in (13) she is 'literally

\footnotetext{
${ }^{6}$ There are in fact two circumstances in which (11) can be felicitous. As one reviewer pointed out, (11) is fine if WHAT-d'you-call-it is interpreted as a reference to a previous utterance, and only secondarily to the chuck key-i.e. in a case where the term WHAT-d'you-call-it had been used previously (i.e. by John), and is being ironically indexed by its use in the present context of identifying the chuck key. This would essentially amount to using the WHAT-d'you-call-it as a proper name for 'the chuck key'. Secondly, as Steve Levinson points out in a personal communication, (11) could also occur in a situation in which the speaker, having uttered the first clause, has become unsure whether chuck key was the right word after all. This would in essence be a repair, signaling a change in the speaker's confidence as to the appropriateness of their choice of words. In this case, the relevant conditions (i.e. what the speaker wants to say about whether she knows the word for the referent) change midstream, allowing (11) to make sense.

${ }^{7}$ I exclude from this discussion the expression Ya know WHAT?, an idiom used for inviting the hearer to take up on the speaker's offer to surprise them with some notable piece of information.
} 
saying' that John knows.] But the expressions WHAT-d'you-call-it and you-knowWHAT do not have the same meaning. We cannot assume that Mary has the same communicative intention in uttering (13) as she has in (1). John receives somewhat different clues for inferring what Mary is talking about. Those clues are apparently in the semantics of the lexical items.

As suggested by the lexical components of you-know-WHAT, the speaker is expressing an assumption that the addressee 'knows what' she is talking about. Semantically, you-know-WHAT has this in common with WHAT-d'you-call-it. But the crucial difference between the two expressions concerns what the speaker communicates about her reason for not saying the word for the thing in mind.

Suppose Mary's utterance in (13) emerged in the same context given for (1). She would no longer be saying that she can't say chuck key, but that she doesn't want to (knowing that she doesn't have to). Perhaps John is accustomed to losing or hiding the chuck key, and she is tired of constantly asking him where it is. By saying youknow-WHAT instead of chuck key, she is underscoring this point, namely that she deliberately chooses not to say the word, since it should be quite clear to John what she is talking about. This has a kind of 'accusing' force, which WHAT-d'you-call-it could not achieve. More commonly, you-know-WHAT may have both 'avoidance' and 'conspiratorial' functions, whereby a speaker deliberately avoids saying a certain word, either to prevent potentially overhearing third parties from understanding, and/or to create a collusive air between interlocutors. Suppose that John and Mary are expatriate Australians in a tropical country, hosting a function for their compatriots. They have had a crate of fresh peaches flown in for the occasion, knowing that their guests would cherish the opportunity to indulge. Once dinner is finished, John says to Mary:

(14) I think it's time to serve the you-know-WHATs.

John could have said peaches, but avoids doing so, presumably to create tension among the guests as to what to expect for dessert, and to allow the sight of the peaches themselves to reveal the surprise. Mary of course is well aware of what John is referring to. Furthermore, overhearing John's utterance in (14), the guests are also well aware that his expression is a deliberate avoidance, excluding them, and intended to be understood by Mary alone. This effect could not be achieved by using WHAT-d'you-call-it, which with different semantics provides different clues for inference about what John must have meant. If he had said I think it's time to serve the WHAT-d'you-call-its, his message would be that he 'can't say' the word. Guests' likely interpretation would be that dessert is going to be something with a fancy name which John has forgotten or can not pronounce. Pragmatics alone can not account for this distinction (see Section 3.2, below).

Here are two more examples of this avoidance/conspiracy function of you-knowWHAT:

(15) Did you bring any you-know-WHAT? (e.g. 'marijuana', to a party)

(16) Look, his you-know-WHAT is not on straight. (e.g. lecturer's 'hairpiece') 
In each case, the reference of you-know-WHAT is crucially dependent on both the situation and the speakers' common ground, and each of the uses may have a rather different implication and/or connotation in different contexts. But despite the lack of descriptive information about the referent itself, the interpretations are not entirely unconstrained. They remain anchored by semantic specifications of you-knowWHAT, namely that the speaker does not want to utter a certain word/expression he is thinking of, because he knows he doesn't have to (since in that context the listener knows or can know what he is talking about).

Based on the preceding discussion, I offer the following paraphrase of you-knowWHAT:

(17) you-know-WHAT

- Something

- I don't want to say the word for this thing now

- I don't say it now because I know I don't have to

- By saying you-know-WHAT I think you'll know what I'm thinking of.

As in the case of WHAT-d'you-call-it, it is presupposed that there is a word for the thing, a specification which narrows possible interpretations. Also as in the case of WHAT-d'you-call-it, you-know-WHAT has a related form, used for reference to people, in which what is replaced by who:

(18) Here comes you-know-WHO.

(19) I saw John at the club again with you-know-WHO.

You-know-WHO (which unlike WHAT'S-his/her-name does not distinguish sex) may thus be paraphrased as follows:

(20) you-know-WHO

- Someone

- I don't want to say this person's name now

- I don't say it now because I know I don't have to

- By saying you-know-WHO I think you'll know who I'm thinking of.

\subsection{Cross-linguistic contrast-Lao qan $^{0}-$ nan $^{4}$ 'that thing'}

Expressions like WHAT-d'you-call-it do not have the same kinds of form and function across languages, and this is an area of linguistic typology about which very little is known. Let us examine a WHAT-d'you-call-it type word from Lao (Southwestern Tai, Laos), namely $q a n^{0}$-nan', literally 'that thing'. 8

Since $q a n^{0}-n a n^{4}$ may simply mean 'that one', there is a range of deictic uses (related either to the discourse or the situational context) which do not concern us here. In contrast to typical deictic usages, in the usage we are interested in, identification 
of a referent is achieved in the absence of any discourse antecedent or contextually present object. Secondly, the nominal is treated grammatically as a predication (i.e. taking aspect and modality marking). Consider the following example: ${ }^{9}$
(21) $m \grave{e}^{1}$

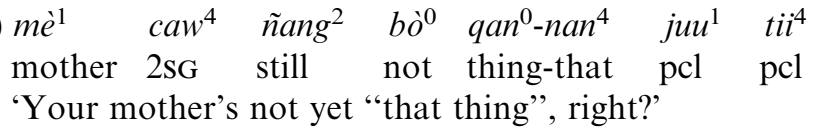

The speaker assumes that my mother is very old, and he is checking that she is still in good health. He uses $q a n^{0}-n a n^{4}$ to avoid explicitly labelling what he has in mind (i.e. something about her being in a bad state of health - 'senile', 'weak', 'crippled', or what have you), presumably because this may be impolite or hurtful to my feelings. Unlike in the case of English WHAT-d'you-call-it or you-know-WHAT, it does not seem that the speaker has specific words in mind (i.e. informants do not suggest specific words he must have meant, but talk in more general terms what he must have been talking about). I suggest that what the speaker conveys here is that he doesn't know how to say what he is thinking of. The likely reason for this in example (21) is that making his thoughts explicit would run the risk of creating an uncomfortable situation.

A second example arises in discussing a poster of King Bhumibol of Thailand on the wall of a shop in Vientiane, the capital city of Laos:
(22) A. $c a w^{4}$ hak ${ }^{1} \quad$ phen $^{1} \quad b \dot{o}^{3}$
2sG love 3hon pcl
'Do you love him?'
B. $k a a^{1} \ldots \quad q a n^{0}-n a n^{4} \quad j u u^{1}$
So... thing-that pcl
'Well, "that thing".'

B's answer is, essentially, 'yes', but she uses $q a n^{0}-n a n^{4}$ 'that thing' as an avoidance strategy, due no doubt to the political sensitivity in Laos of openly declaring one's love of the Thai king. The Lao royal family met its demise in the socialist revolution of 1975. Recently, increased exposure to neighbouring Thai culture has involved Lao speakers in the fervent monarchism of their neighbours (Evans, 1998, 1999; Enfield, 1999b). While the Thai king is well-liked by many Lao people, there is

\footnotetext{
${ }^{8} \operatorname{Qan}^{\circ}$ is a classifier which in numeral classifier contexts is typically used with reference to "small things that can be held in the hand', but which in contexts of modifiers and/or specifiers (such as the demonstrative $\operatorname{nan}^{4}$ 'that') has more general semantics, meaning simply 'thing' (Enfield, in press). There are two genuine demonstrative determiners in the Lao system, nii ' 'this' (neutral) and nan ' 'that' ('non-proximal'). With these meanings, nit $^{4}$ 'this' and nan $^{4}$ 'that' cannot be used independently of their nominal classifier heads. $\mathrm{Nii}^{4}$ may be used without a classifier nominal head, in which case it has the adverbial meaning 'here', along with three other spatially deictic adverbials phii 'right here', han $^{5}$ 'there', and phun 'yonder'.

9 Lao examples are attested and re-checked/discussed with informants. Abbreviations are: $2 / 3$ (second/ third person pronominals); hon (honorific); pcl (particle); foc (focus). Numerals on lexical items indicate lexical tones.
} 
naturally a tension arising from the fundamental association of the Thai monarchy with Thai nationalism on the one hand, and being a Lao national, on the other. By using the expression $q a n^{0}-n a n^{4}$ 'that thing' in (22), the speaker communicates that she doesn't know how (best) to say what she wants to say (namely, 'yes').

In the next example, the speaker has just asked me if I paid Lao Kip or foreign currency for a recent purchase. At this time, the exchange rate for Lao currency was much in favour of the dollar, and he knew that the shop would have preferred to take dollars. If I paid in Lao Kip, then I got a good deal. I replied that I did indeed pay in Lao currency, and he asked:

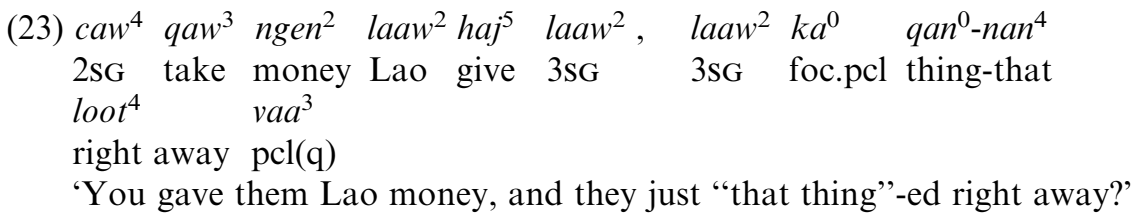

The speaker is avoiding explicitly referring to the exchange of money for goods, perhaps for two reasons. First, to talk openly about money and financial deals is to an extent socially restricted, at least on a less informal level such as the context in which (23) was uttered. Rachel Dechaineaux (personal communication) describes a meeting in which Lao officials used $q a n^{0}-n a n^{4}$ 'that thing' repeatedly to refer to their own low salaries and their need for a pay-rise. Lao people are generally reticent to voice their desire for change, especially in public contexts, and in this case employees found the idea of asking directors for a raise so face-threatening that apparently noone could bring themselves to utter the words required. Not knowing how to say what they wanted to say, speakers used $q a n^{0}-n a n^{4}$ 'that thing' instead. (Note that neither you-know-WHAT nor WHAT-d'you-call-it would be appropriate in English in the same situation.)

A second factor which may have encouraged the speaker of (23) to use $q a n^{0}-n a n^{4}$ 'that thing' for avoidance may relate to a superstition about openly mentioning anything to do with good luck, or lucky deals that are not yet confirmed. Since the purchase in question was a brand new item, and since the speaker suspects I was getting a good deal, it is possible that he did not want to risk 'ruining' that by openly referring to it.

The examples of $q a n^{0}-n a n^{4}$ 'that thing' have so far all been euphemistic, i.e. means for avoiding saying something that could be taken badly, signalling that the speaker doesn't know how (best) to put it. However, people may also use qan ${ }^{0}-n a n^{4}$ 'that thing' with a similar function not due to any perceived risk of social transgression, but because they simply do not know how to put into words what they want to say. For example, a Lao speaker trying to follow a telecast of the unfamiliar sport known as rugby league said the following:

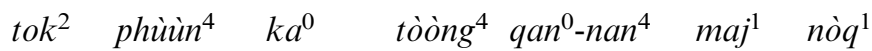

$$
\begin{aligned}
& \text { fall ground foc.pcl must thing-that new pcl } \\
& \text { '(When they) fall (to the) ground, (they) have to "that thing" again, right?' }
\end{aligned}
$$


The speaker is referring to a constantly recurring event in the course of a rugby league match in which, after a momentary pause in proceedings following the tackling and grounding of a player who is in possession of the ball, play resumes with the tackled player getting up, facing forward, and raking the ball, under one foot, back to another player on his own team. This 'raking' of the ball back to one's team-mate is referred to in English as playing the ball. There is no term for this in Lao. The speaker of (24) did not know how to refer to playing the ball, and indeed had no idea whether there was a name for it at all. This use of $q a n^{0}-n a n^{4}$ 'that thing' is subtly distinct from English speakers' use of WHAT-d'you-call-it, where the speaker knows or assumes that there is a word, and wants to signal that he just can't say it (e.g. because he can't think of it). In the Lao case it is more a matter of 'not knowing how to say' what the speaker wants to say, due either to being literally unable to verbalise the thought, or to a judgement that the words one has in mind are inappropriate for one reason or another and are therefore not 'the way to say it'.

The following paraphrase definition is intended to capture the range of uses of $q a n^{0}-n a n^{4}$ 'that thing' illustrated in examples (21-24), above:

(25) $q a n^{0}-n a n^{4}$ 'that thing'

- Something (happens/is the case)

- I don't know how to say what I'm thinking of

- By saying $q a n^{0}-n a n^{4}$ ('that thing') I think you'll know what I'm thinking of.

The above discussion has shown that the typical implication of 'avoidance', shown most clearly in examples (21) and (22), is not a semantic specification of qan ${ }^{0}-n a n^{4}$ 'that thing', but emerges in context from a more general specification that the speaker 'doesn't know how to say' what he wants to convey. Whether this is due to social, cognitive, or other constraints depends on the context. The more general phrasing of (25) allows it to cover not only the 'avoidance' examples, but also examples like (24) which seem closer to the likes of WHAT-d'you-call-it. In all cases, $q a n^{0}-n a n^{4}$ 'that thing' communicates the speaker's assumption that the listener will know what is meant.

\section{Discussion}

So far we have concentrated on a range of specific examples of WHAT-d'you-call-it type expressions, with attempts to account for the data by proposing specific 'inference-constraining' semantic content in each case. We now turn to a number of theoretical and methodological matters which the reader will no doubt have been considering already.

\section{1. 'Recognitional deixis'}

Expressions like WHAT-d'you-call-it are not found among the phenomena usually listed as examples of 'deixis' (Lyons, 1977: Chapter 15; Levinson, 1983: Chapter 2; 
Anderson and Keenan, 1985, inter alia). However, one important reason for arguing that they are deictic is that their meanings [as proposed, for example, in (2), above] contain components like 'I', 'you', 'this' and 'now', which are deictics par excellence. [Wilkins (1992: 132) uses this, among others, as an argument for considering interjections as deictics.] Indeed, they present particularly interesting cases of deixis in that they define as the search domain for establishment of reference the set of interrecursive assumptions defining interlocutors' 'common ground' (Clark, 1996a, b; Enfield, 2000). They have what Sacks and Schegloff (1979) call 'recipient design', and as such may be labelled 'recognitionals', i.e. 'reference forms [which] invite and allow a recipient to find, from some "this-referrer's-use-of-a-reference-form" on some "this-occasion-of-use," who [or what; NJE], that recipient knows, is being referred to' (Sacks and Schegloff, 1979: 17). These authors concentrate on reference to persons, not things, and are mostly interested in the use of names. However, expressions like WHAT-d'you-call-it are clearly 'recognitional' in the relevant sense. As the discussion so far has shown, their use becomes possible if recipient may be supposed by speaker to know the one being referred to, and if recipient may suppose speaker to have so supposed' (Sacks and Schegloff, 1979: 17). Himmelmann (1996: 230ff) has used this sense of 'recognitional' to label a particular usage of demonstratives, and the Lao expression discussed in Section 2.3, above, is one example of just this special function.

Relatively little attention has been paid to the theory and description of recognitional deixis, this little understood and little explored function of deictic expressions. Further research, especially of a cross-linguistic nature, is required.

\subsection{Semantics or pragmatics?}

Some may want to suggest that the meanings proposed in various paraphrase definitions in Section 2, above, are not part of semantics but rather pragmatics. I maintain, however, that the proposed meanings do belong in semantics, assuming that 'semantic meaning' refers to what is communicated by a linguistic sign contextindependently and non-defeasibly. In other words, the claim here is that one can't be saying WHAT-d'you-call-it and not be saying 'I can't say the word for this thing now' and 'I think you'll know what I'm thinking of'. ${ }^{10}$ One might imagine a context in which the speaker of (1) really can think of the word, yet for some reason wants to avoid using it. But this would not change what is being said. That the utterance in (1) means 'I can't say the word for this thing now' does not mean that the speaker actually cannot at that time say the word for the thing. It means that the speaker is saying that she cannot at that time say the word for the thing. Whether it is true is irrelevant to the semantics of the expression and/or its effects in communication-

\footnotetext{
10 One issue I can not get into here concerns the status of these meanings as being of one 'kind' or another - e.g. whether they involve 'entailments' or 'presuppositions', 'procedural' or 'propositional' specifications, and so on. These more detailed considerations must be reserved for further research on this problem.
} 
just as delicious in This soup is delicious entails (among other things) 'tastes good', even if I find the soup unstomachable (and regardless of whether I want you to believe that I think it tastes good, i.e. of whether I am lying or just being sarcastic). Thus, I know one instance of a speaker persistently using WHAT's-his-name to refer to a particular person (her son-in-law), even though she is well aware of his name. This speaker is able to take advantage of the stable meaning of WHAT's-his-name to persistently act as if she can not think of the referent's name, thereby naturally achieving a routine assertion of emotional distance. These pragmatic effects depend on stable semantics, along the lines proposed in Section 2, above.

\subsection{Meaning or 'conditions of use'?}

According to one view (e.g. that of relevance theorists such as Nicolle (1998) and references therein), semantic components of the kind proposed in Section 1, above, could constitute 'conditions of use' rather than 'meaning'. However, it is not clear to me that such a distinction is applicable. The bottom line in a Gricean type model is that a communicated idea either (a) is part of the stable specifications of a sign, or (b) emerges via inference as generated by those stable specifications in combination with aspects of the total context. The components of meaning explicated in, for example, (2) are among the sign's stable specifications, and are not merely disembodied 'instructions' for when and/or how to use the expression WHAT-d'you-call$i t$. They represent what the speaker conveys to the hearer whenever the term is used, and as such they constitute part of the meaning of the expression. It is true that these semantic components make markedly different specifications from referent-descriptive 'propositional' meanings found in words like table and carburettor, and this is no doubt what would lead some traditions to regard meanings such as those explicated in (2), (17), and (25), above, as 'procedural' (cf. Nicolle, 1998, inter alia). The proposed meanings do not specify properties of the referent itself, but make reference to speaker, hearer, speech act, and assumed-to-be-assumed-to-be-mutuallyshared knowledge. This puts WHAT-d'you-call-it type expressions in a special domain of meaning, but it is not clear that they convey a 'type' of meaning cut from different cloth.

\subsection{Grammaticalisation/lexicalisation}

How distinct is the lexical expression WHAT-d'you-call-it from the syntactically compositional expression WHAT do you CALL it? First, they show significant differences in grammatical distribution, one being a complex and independent sentence asking an explicit question about the addressee's speech act of 'calling', the other referring to a thing, and, accordingly, behaving like a nominal. Second, they show corresponding formal contrast in stress/intonation (WHAT-d'you-call-it versus WHAT do you CALL it?). The following examples show that the intonationally distinct expressions are appropriate for different contexts (with relative stress and pitch of syllables represented by size and height of the ' $\sigma$ ' below the phonetic transcriptions): 
(26) (a) Where's the WHAT-d'you-call-it? $\quad\left[{ }^{1} \mathrm{WDd}_{3} \mathrm{zk}^{\mathrm{h}} \mathrm{\jmath} \mathrm{l} \partial \mathrm{t} \mathrm{t}^{\mathrm{T}}\right]$

$\left[\begin{array}{llll}\sigma & \sigma & \sigma & \sigma\end{array}\right]$

(b) *Where's the WHAT do you CALL it? $\left[{ }^{1} \mathrm{Wotduju}^{1} \mathrm{k}^{\mathrm{h}} \mathrm{sl} \mathrm{bt}\right]^{11}$

$\left[\begin{array}{lllll}\sigma & \sigma & \sigma & \sigma & \sigma\end{array}\right]$

(27) (a) That's an unusual painting-WHAT do you CALL it? $\left[{ }^{1} \mathrm{Wotduju} \mathrm{u}^{1} \mathrm{k}^{\mathrm{h}} \mathrm{\jmath} \mathrm{l} \mathrm{t}\right]$

$\left[\sigma_{\sigma} \sigma \sigma_{\sigma}\right]$

(b) *That's an unusual painting —WHAT-d'you-call-it? $\quad\left[{ }^{1} \mathrm{WDd}_{3} \mathrm{~K}^{\mathrm{h}} \mathrm{ol} \mathrm{\partial t}\right]$

$\left[\begin{array}{cccc}\sigma & \sigma & \sigma & \sigma\end{array}\right]$

Another obvious grammatical difference between the lexicalised expression WHATd'you-call-it and the sentence What do you call it? concerns the possibilities for tense/ aspect marking. Thus, we find What will you call it? and What will you have called it?, but not *Where's the WHAT-will-you-call-it? or *Where's the WHAT-will-you-havecalled-it?. Note, however, that in the lexicalised expression both gender (WHAT's-hisname versus WHAT's-her-name) and number (I found some WHAT-do-you-call-them) may be marked. Number-marking is revealing of the status of WHAT-d'you-call-it as a unitary lexical item, since it may also take simple-s plural marking (unlike independent it):

(28) (a) John gave WHAT-d'you-call-it to Mary for her birthday.

(b) John gave WHAT-d'you-call-its to Mary for her birthday.

(29) (a) John gave it to Mary for her birthday.

(b) *John gave its to Mary for her birthday.

In semantic terms, the lexical and compositional expressions are clearly distinct. WHAT-d'you-call-it does not pose a question. If I say I've put the WHAT-d'you-call-it back in the toolbox, I am not asking you anything, nor am I referring to a speech act I think you have made or that I expect you would make or could have made. There is obviously a derivational relationship between the nominal WHAT-d'you-call-it and the question WHAT do you CALL it?, but the relationship is not one of online derivation in individual instances.

A similar relationship pertains between you-know-WHAT (a nominal) and You know what... (a declarative sentence). While in this case the stress/intonation distinction is less obvious, there remains a functional distinction between the lexical and compositional expressions. Compare the following:

11 Example (26b) is distinct from the following, although it consists of the same constituents in the same order:

(i) Where's the-WHAT do you CALL it? $\quad\left[{ }^{1} \mathrm{wDt} \mathrm{du} \mathrm{ju}{ }^{1} \mathrm{k}^{\mathrm{h}} \mathrm{ol}\right.$ ət]

$\left[\begin{array}{lllll}\sigma & \sigma & \sigma & \sigma & \sigma\end{array}\right]$

In this case, the two parts of the utterance must be intonationally distinct in a way not necessary in (26a). Importantly, in (i) WHAT do you CALL it? is not a constituent of what comes before, and what comes before it is truncated. Here, WHAT do you CALL it? is a genuine question. 
(30) (a) I saw you-know-WHO at the club.

(b) You know who I saw at the club.

Example (30a) states 'who I saw', while (30b) states 'what you know'. To be sure, (30a) also refers to what you know, but this is not the sentence-level focus. The two utterances are distinct in a way in which the following are not:

(31) (a) I saw John at the club.

(b) John I saw at the club.

Both (31a) and (31b) state 'who I saw'.

Another sign of grammaticalisation here is the possibility of plural-marking on the whole expression you-know-WHAT, while the same is odd, if possible at all, for the word what (either independently or in the compositional expression You know what):

(32) John served you-know-WHATS for dessert.

(33) (a) John served what for dessert?

(b) ??John served whats for dessert?

Thus, the two English terms WHAT-d'you-call-it and you-know-WHAT are lexicalised, as both semantic and phonological distinctions with their non-lexical counterparts reveal. They have apparently travelled a path from being sentences (in one case a question about 'what you call it', in the other a statement about 'what you know') to being nominals. ${ }^{12}$ Given that they are distinct from their co-existing non-lexical source structures, it is important to be careful how much stock is put in what is 'literally stated' in the lexical expressions. The fact that the morphology of WHAT-d'you-call-it 'literally' asks 'What do you call it?' does not mean that the expression means 'What do you call it?', just as when fork means 'eating implement' it does not mean 'point where branch splits in two'. Once satisfied that an expression has two distinct meanings, the two meanings must be defined each on their own terms, and only then may one ask how they are related, and how 'literal' readings may be relevant. While the perceivable semantic relationships between polysemous expressions do not generate one expression from the other 'online', they nevertheless do have iconic indexical value. That is, while one cannot make a priori predictions about the precise relationship between two meanings of a single word or expression, one can find, after the two meanings are known, mnemonic 'motivations' or 'explanations' for the meanings the word or expression happens to have (Keysar and Bly, 1999; Enfield, 2002). So the relation between lexical WHAT-d'you-call-it and nonlexical What do you call it? is ultimately a secondary issue here.

Formal distinctions in stress/intonation of the kind observed for WHAT-d'you-callit and you-know-WHAT and their non-lexical counterparts are not available for $q a n^{0}$ -

12 Lakoff's (1974) discussion of 'syntactic amalgams' is suggestive of mechanisms whereby this process might begin. (Thanks to Steve Levinson for drawing my attention to this reference.) 
$n a n^{4}$ 'that thing' in Lao. However, there are clear distinctions in grammatical behaviour between recognitional and other uses of $q a n^{0}-n a n^{4}$ 'that thing'. The most obvious distinctive feature of the recognitional uses discussed here is their grammatical treatment as predicates (i.e. taking negation and other definitive verbal marking, as illustrated in examples (21-24), above). This functional 'extension'-from nominal to predicative - is thus in the opposite direction to that of WHAT-d'you-callit and you-know-WHAT in English, which as we have seen are 'extensions' from predicative to nominal expressions.

\subsection{Convention}

An intriguing final question concerns the level of conventionality of dedicated recognitional expressions such as WHAT-d'you-call-it and you-know-WHAT. Firstly, it is clear that WHAT-d'you-call-it and many similar words are widely known and used English lexical forms. The Collins English Dictionary (CED, 1979) includes entries for not only what-d'you-call-it, but also doodah, doodad, hootenanny, thingamabob, thingamajig, whats-her-name, whatsit, and others. These are widely known and recognised among English speakers. But are these just variants of WHAT-d'you-call-it with the same meaning? Or do their specifications differ in subtle but definable ways? The comparison of WHAT-d'you-call-it and you-know-WHAT in Section 2, above, shows that one cannot assume two recognitional expressions to be functionally identical. The question is ideally approached with reference to natural examples.

Beyond the more conventionalised expressions just mentioned, there seems to be a level of productive 'derivation' of recognitionals in English, based on (morpho-) phonological similarity to prototypes such as WHAT-d'you-call-it and thingamajig. There are many less-well-known and even entirely novel blends and variations along the lines of dooziewhatsit, thingamedoodad, and whatchamajig, and no doubt dozens more. However, and importantly, there remain conventionalised boundaries on the formal possibilities. The listener must still be able to guess from the form that a recognitional expression is intended, i.e. that the form is meant as a substitute for a word the speaker could have used. Were a creative speaker to step beyond the licensing morpho-phonological conventions (e.g. by asking Where's the foon?, where foon has no hint of phonological similarity to WHAT-d'you-call-it or thingamajig), no recognitional function would be achieved. Listeners would assume that foon was a word which the speaker meant to use, and which was simply unknown to the listener.

Finally, with regard to convention and productivity, it is important to note that WHAT-d'you-call-it type expressions can be conventional on the 'personal' as well as 'communal' levels (Clark, 1996b). Their 'recipient design' (Sacks and Schegloff, 1979) makes them well suited to being coined, with exclusive forms, as in-group conventions. With an exclusive form - say, hooterflanger-known and used within an exclusive group of speakers (as few as two), such an expression is designed for recipients within just that group. Working as they do with explicit reference to what is shared between interlocutors, dedicated recognitionals naturally arise in 'private' contexts. When speakers share not just the necessary knowledge for recovery of a 
referent given no descriptive information, but also knowledge of a unique (suppletive?) phonological form as a private signal that such recovery is called for, their solidarity is doubly underlined.

\section{Concluding remarks}

Little is known about the status of recognitional expressions cross-linguistically. Do all languages have dedicated and conventionalised recognitional expressions? How often are these transparently derived? How often are they related to propositions, as in English, and how often to demonstratives or other deictic expressions, as in Lao? How often are there productive means for generating such expressions, on both 'communal' and 'personal' levels? This is fertile and fascinating ground for further investigation.

Words of the WHAT-d'you-call-it variety are intriguing manifestations of the fundamentally interactional and cooperative character of language. Speakers constantly monitor and take into account the interactional context and the common ground of interlocutors in order to successfully communicate. Recognitional expressions like WHAT-d'you-call-it enshrine in their very meanings the notion of reference as a 'joint project', and these simple but effectively stable semantic specifications provide anchoring information, constraining and guiding inference, and accounting for contrast with similar semantically general expressions. Beyond these slim semantics remains the uncanny ability of interlocutors to figure out each others' communicative intentions with apparently so few clues.

\section{Acknowledgements}

I am indebted to Steve Levinson, Jürgen Bohnemeyer, and two anonymous reviewers for helpful criticism on drafts of this paper. Cliff Goddard's input on an early version (Enfield, 1999a) is also gratefully acknowledged. Faults which remain are my responsibility.

\section{References}

Anderson, Stephen R., Keenan, Edward L., 1985. In: Shopen, Timothy (Ed.), Language Typology and Syntactic Description, Vol. III. Cambridge University Press, Cambridge, pp. 259-308.

CED, 1979. Collins Dictionary of the English Language. Collins, Sydney/Auckland/Glasgow.

Clark, Herbert H., 1996a. Using Language. Cambridge University Press, Cambridge.

Clark, Herbert H., 1996b. Communities, commonalities, and communication. In: Gumperz, John J., Levinson, Stephen C. (Eds.), Rethinking Linguistic Relativity. Cambridge University Press, Cambridge, pp. 324-355.

Enfield, N.J., 1999a. On the indispensibility of semantics: defining the 'vacuous'. Rask 9/10, $285-304$.

Enfield, N. J. 1999b. Lao as a national language. In Evans (Ed.), Laos: Culture and Society, pp. 258-290.

Enfield, N.J., 2000. The theory of cultural logic: how individuals combine social intelligence with semiotics to create and maintain cultural meaning. Cultural Dynamics 12 (1), 35-64. 
Enfield, N.J., 2002. Semantic analysis of body parts in emotion terminology: avoiding the exoticisms of 'obstinate monosemy' and 'online extension'. Pragmatics and Cognition 10 (1/2), 81-102.

Enfield, N. J., in press. Nominal classification in Lao: a sketch. In Sprachtypologie und Universalienforschung.

Evans, Grant, 1998. The Politics of Ritual and Remembrance: Laos Since 1975. Silkworm Books, Chiang Mai.

Evans, Grant. (Ed.), 1999. Laos: Culture and Society. Silkworm Books, Chiang Mai.

Goddard, Cliff, 1998. Semantic Analysis: A Practical Introduction. Oxford University Press, Oxford.

Himmelmann, Nikolaus P., 1996. Demonstratives in narrative discourse: a taxonomy of universal uses. In: Fox, Barbara (Ed.), Studies in Anaphora. John Benjamins, Amsterdam, pp. 205-254.

Keysar, Boaz, Bly, Bridget Martin, 1999. Swimming against the current: do idioms reflect conceptual structure? Journal of Pragmatics 31, 1559-1578.

Lakoff, George, 1974. Syntactic amalgams. Proceedings of the Chicago Linguistics Society, pp. 321-344.

Levinson, Stephen C., 1983. Pragmatics. Cambridge University Press, Cambridge.

Levinson, Stephen C., 1995. Interactional biases in human thinking. In: Goody, Esther (Ed.), Social Intelligence and Interaction. Cambridge University Press, Cambridge, pp. 221-260.

Lyons, John., 1977. Semantics. Cambridge University Press, Cambridge.

Nicolle, Steve, 1998. A relevance theory perspective on grammaticalization. Cognitive Linguistics 9 (1), 135.

Sacks, Harvey, Schegloff, Emanuel, 1979. Two preferences in the organisation of reference to persons in conversation and their interaction. In: Psathas, Gerorge (Ed.), Everyday Language. Irvington, New York, pp. 15-21.

Wilkins, David P., 1992. Interjections as deictics. Journal of Pragmatics 18, 119-158.

Nick Enfield is a scientific staff member at the Max Planck Institute for Psycholinguistics in Nijmegen. He is interested in a multidisciplinary approach to semiotic phenomena, including descriptive and functional linguistics, cognitive/conceptual approaches to semantics, the study of gesture and other non-verbal behaviour, and ethnography. He has conducted sustained fieldwork research in Laos and other countries of mainland Southeast Asia. 